\title{
Weldability of Galvannealed Interstitial Free Steel
}

\author{
C. A. CAMPOS, M. P. GUERRERO-MATA, R. COLÁS and R. GARZA ${ }^{1 \prime}$
}

Facultad de Ingeniería Mecánica y Eléctrica, Universidad Autónoma de Nuevo León, A.P. 149-F, 66451 San Nicolás de los Garza, N.L., México. $\quad$ 1) Galvak, S.A. de C.V., Juventud 340 Nte., 66450 San Nicolás de los Garza, N.L., México.

(Received on August 27, 2001; accepted in final form on May 20, 2002)

\begin{abstract}
A series of interstitial free steel strips were subjected to different annealing treatments after being galvanized by immersion. Samples from these strips were cut and various tests were carried out on them. The coating was studied by optical and scanning electron microscopy, analysis of the X-ray spectra was conducted on the samples while being observed in the latter equipment. Resistance to powdering of the coating was studied by means of V-bend testing. Spot resistance welding tests were conducted by varying the current supplied by the machine, different geometrical parameters and the resistance of the welded joint were evaluated. It was found that the amount of powdering of the coating increased as the amount of $\Gamma$ phase augmented, as well as with the increment in coating thickness. The mechanical strength of welded strips was found to improve with the increment in welding current, up to the point where expulsion of material was occurred.
\end{abstract}

KEY WORDS: interstitial free steels; galvannealing; weldability; microscopy; powdering.

\section{Introduction}

Galvannealing has become one of the most important processes to assure higher corrosion resistance in steels. These materials exhibit better adhesion and response to organic coatings, as well as better weldability and higher formability, than other zinc coated products. Of these characteristics, corrosion resistance and weldability depend on the iron content within the coating, whereas formability depends on the structure of the coating, and it is sensitive to the presence of intermetallic phases. ${ }^{1-5)}$ A drawback of galvannealed strips is their tendency for powdering and flaking during press-forming. Powdering has been attributed to the occurrence of hard and brittle intermetallics, mainly $\Gamma$, within the coating, whereas flaking is thought to be due to the presence of an excessive amount of phase at the surface. $^{3-8)}$

Some authors ${ }^{1,2,4,5)}$ have found that resistance to powdering decreases with increasing coating weight, galvannealing temperatures, iron content within the coating and the reduction of $\mathrm{Al}$ content in the bath. It has also been suggested ${ }^{9)}$ that powdering resistance deteriorates as the thickness of the $\Gamma_{1}$ phase $\left(\mathrm{Fe}_{5} \mathrm{Zn}_{21}\right)$ increases; presence of $\zeta$ phase $\left(\mathrm{FeZn} \mathrm{n}_{13}\right)$, together with $\Gamma_{1}$, deteriorates the coating in operations in which friction plays an important roll, ${ }^{2)}$ whereas, in frictionless conditions, $\zeta$ phase would be beneficial due to relaxation of surface stresses, improving resistance to powdering. ${ }^{8,10}$ ) The development of high $\mathrm{Fe}$ content $\delta_{1}$ phase has been associated with the increment of the tendency for powdering. ${ }^{4,6)}$

Resistance welding is commonly use to join galvannealed sheets in automotive industry. This process relies on a combination of pressure and heat to produce a joint be- tween different pieces. The heat for welding is generated by the resistance to flow of electrical current through the parts being joined. This heat may be expressed by ${ }^{11-15)}$ :

$$
H=I^{2} R t
$$

where $H$ is the heat, $I$ the current, $\mathrm{R}$ the resistance and $t$ the time of current flow.

It has been reported ${ }^{16,17)}$ that the surface roughness of the strips do not exert a significative effect on welding parameters, as roughness disappears after a very short time has elapsed. It has also been claimed ${ }^{14,18,19)}$ that the current required to obtain an acceptable joint increases with the increment of coating weight.

The aim of this work is to present the parameters that were found to affect the behavior of galvannealed strips made from interstitial free steels. A series of tests were conducted to evaluate the resistance to powdering and weldability on samples cut from various strips produced in an industrial plant.

\section{Experimental Procedure}

The present study was conducted on samples from four different $\mathrm{Ti}$ stabilized interstitial free steels strips of 1.15 mm thickness (Table 1). The material had a $68 \%$ cold rolled reduction, and was degreased, annealed in a continu-

Table 1. Chemical composition (wt \%) of the interstitial free steels.

\begin{tabular}{cccccccccc}
\hline Batch & $\mathrm{C}$ & $\mathrm{Mn}$ & $\mathrm{P}$ & $\mathrm{S}$ & $\mathrm{Si}$ & $\mathrm{Nb}$ & $\mathrm{Al}$ & $\mathrm{Ti}$ & $\mathrm{B}$ \\
A & 0.002 & 0.110 & 0.006 & 0.008 & 0.005 & 0.007 & 0.034 & 0.042 & 0.002 \\
$\mathbf{B}$ & 0.002 & 0.110 & 0.006 & 0.008 & 0.005 & 0.007 & 0.034 & 0.042 & 0.002 \\
C & 0.002 & 0.140 & 0.010 & 0.007 & 0.006 & 0.007 & 0.033 & 0.035 & 0.003 \\
D & 0.002 & 0.120 & 0.007 & 0.007 & 0.005 & 0.006 & 0.036 & 0.037 & - \\
\hline
\end{tabular}


ous furnace set to $800^{\circ} \mathrm{C}$, immersed in a molten zinc bath held at $460^{\circ} \mathrm{C}$ and galvannealed in a induction furnace set to the power range shown in Table 2. The amount of aluminum in the molten bath and the resulting coating weight $^{20)}$ are shown in Table 2. The strips were temper rolled after their galvannealing. The roughness in the coating was measured (Table 2).

Selected samples from various strips were subjected to their analysis by optical and scanning electron microscopy, observations in the later equipment were made with the secondary and backscattered electron detectors, variation of the iron content profile within the coating was obtained by the analysis of punctual X-ray spectra produced by the electron beam.

Small rectangular samples ( 90 by $30 \mathrm{~mm}$ ) were cut from the galvannealed strips to study the powdering of the coating by deforming them in a press to which a V-bend device was installed. These trials were carried out with the $\mathrm{V}$ dies machined to 60 and $90^{\circ}$, the specimens were placed on an anvil, deformed to the angle machined into the dies and straightened after testing. The samples before and after testing were cleaned in a mixture of acetone and alcohol. An adhesive tape was applied to the deformed samples to remove the powder formed on the surface. The weight loss $\left(w_{1}\right)$ was normalized by dividing it by the surface area of the strip $\left(A_{\mathrm{s}}\right)$ to obtain the powder lost $\left(P_{\mathrm{L}}\right)$ by the coating ${ }^{5}$ :

$$
P_{\mathrm{L}}=\frac{w_{1}}{A_{\mathrm{s}}}
$$

where $w_{1}$ loss is obtained by subtracting the weight after testing $\left(w_{\mathrm{f}}\right)$ from the original one $\left(w_{\mathrm{o}}\right)$.

Other strips were cut from different coils to obtain the experimental samples to be spot welded in a two-electrode machine following the procedure described elsewhere. ${ }^{21)}$ The force applied to hold in position the samples was kept constant at $3530 \mathrm{~N}$, the weld cycle was also kept constant. Two sets of specimens were made, those of the first one were cut to measure the weld nugget diameter and the indentation that the electrodes left on the strips. Samples

Table 2. Processing variables and roughness of the samples studied.

\begin{tabular}{lcccccc}
\hline Batch & \multicolumn{2}{c}{ Heating power $(\mathrm{kW})$} & Al in bath & Coating weight & \multicolumn{2}{c}{$\boldsymbol{R}_{a}(\mu \mathrm{m})$} \\
& Minimum & Maximum & $(\%)$ & $\left(\mathrm{g} / \mathrm{m}^{2}\right)$ & $\mathrm{RD}$ & $\mathrm{TD}$ \\
A & 500 & 700 & 0.13 & 143 & 2.06 & 1.91 \\
B & 380 & 500 & 0.13 & 119 & 1.98 & 1.84 \\
C & 200 & 300 & 0.13 & 110 & 1.59 & 1.85 \\
D & 240 & 260 & 0.14 & 110 & 1.43 & 1.39 \\
& & \multicolumn{4}{c}{ RD: Rolling direction } \\
& & & TD: $90^{\circ}$ to RD \\
\hline
\end{tabular}

from the second set were tested in tension in a servohydraulic testing machine at a constant crosshead speed following industrial standards. ${ }^{21,22)}$ An extra set of specimens were prepared from uncoated strips (the coating was dissolved with a $10 \% \mathrm{HCl}$ solution in water) of the material identified as $\mathrm{C}$, see Table 1.

\section{Results and Discussion}

Table 2 shows that the average roughness $\left(R_{\mathrm{a}}\right)$, that is expressed by the vertical deviation from the center line of a given profile on both galvannealed surfaces of the strips, ${ }^{23}$ ) was measured in the directions transversal and parallel to that of rolling, and results to be affected by the power settings used in galvannealing, although were temper rolled. The cross sectional view of the coating was studied by optical and scanning electron microscopy (SEM). Figure 1 shows the SEM micrographs of the four samples, in which a series of cracks can be appreciated. Table 3 presents the average and standard deviation of the thickness calculate after more than twenty different specimens of each type of sample were studied.

Variation of the iron content within the coating, Fig. 2, was obtained by semiquantitative analysis of punctual Xray spectra made on the zinc layer. The average contents of iron shown in Fig. 2 and Table 3 are the result of integrating the profile over the thickness. The profiles shown in Fig. 2 were used to evaluate the individual thicknesses of the different intermetallic phases within the coating assuming that they were stratified and that the iron content of each was that of equilibrium at $500^{\circ} \mathrm{C}$. ${ }^{24}$

High magnification observation, by SEM, put in evidence the presence of crystals of two different sizes on the surface of the coatings. Such an example can be appreciated in Fig. 3, that shows the surface of sample D as observed with the backscattered electrons (BE) detector installed in the SEM; the cracks also observed correspond to those described in Fig. 2. Punctual X-ray analysis were conducted in either type of crystal, yielding the differences of $\mathrm{Fe}$ and Al shown in Table 4. Previous studies of galvannealed steels ${ }^{5,25,26)}$ have concluded that the small crystals are made of $\delta$ phase, whereas the bigger ones correspond to $\zeta$, that reflect the changes detected in chemical composition. A schematic diagram describing the phases present in the coatings of the different samples is shown in Fig. 4, as the tendency for different proportions of $\zeta$ and $\delta$ crystals will change as the power settings during galvannealing are varied.

The tendency for powdering of the different samples was

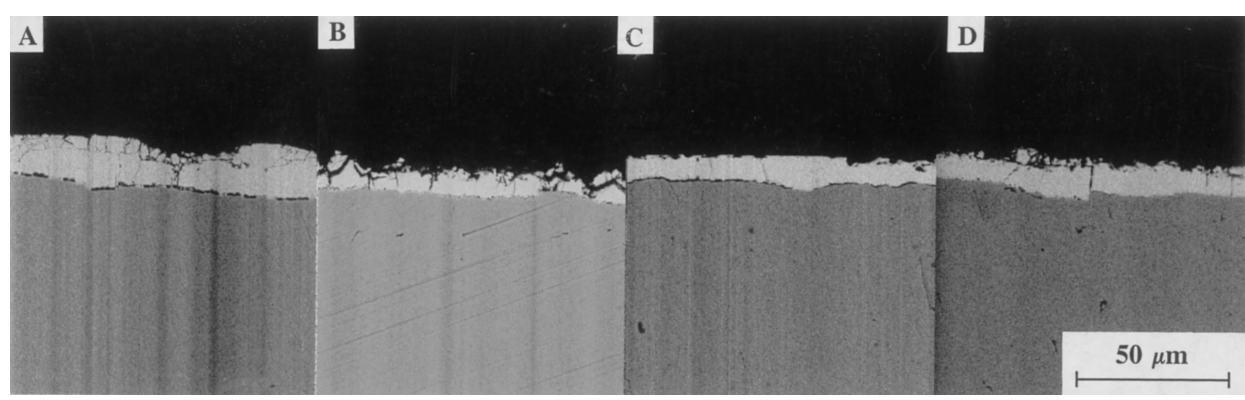

Fig. 1. Cross-section of the coated interstitial free steel samples, SEM images produced by backscattered electrons. 
Table 3. Results from the analysis of the coating profile.

\begin{tabular}{ccccccc}
\hline Batch & \multicolumn{2}{c}{ Coating thickness $(\mu \mathrm{m})$} & Average Fe & \multicolumn{3}{c}{ Phase thicknesses $(\mu \mathrm{m})$} \\
& average & standar dev & $(\%)$ & $\Gamma$ & $\delta$ & $\zeta$ \\
A & 13.09 & 3.13 & 9.75 & 1.40 & 11.10 & 0.50 \\
B & 11.18 & 2.06 & 12.40 & 1.25 & 7.50 & 1.00 \\
C & 10.11 & 2.41 & 11.41 & 1.25 & 7.30 & 1.50 \\
D & 9.54 & 1.88 & 9.14 & 0.90 & 6.10 & 2.50 \\
\hline
\end{tabular}

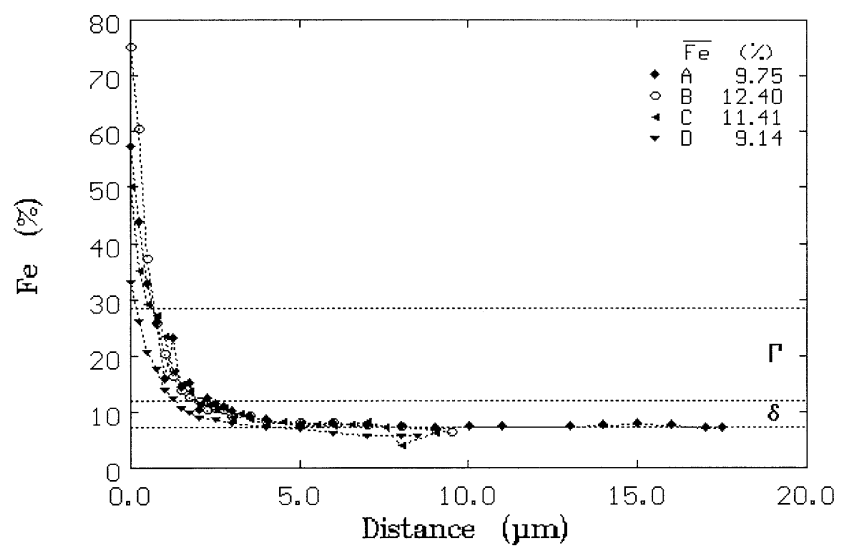

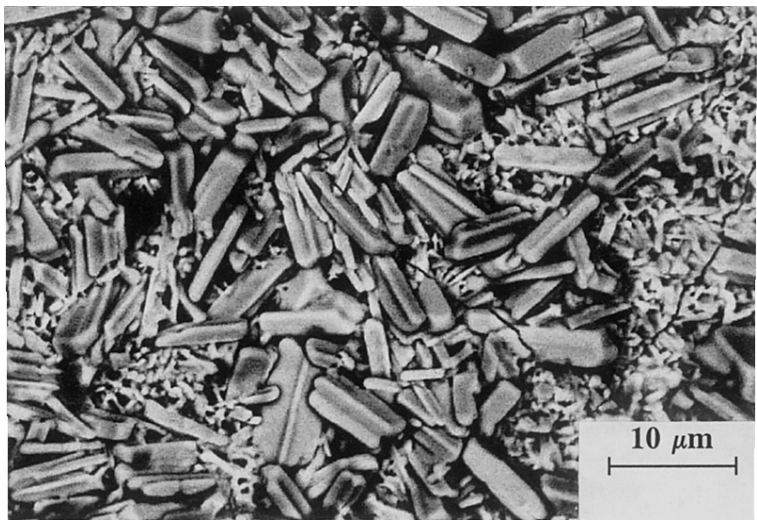

Fig. 3. Backscattered electrons image of the mode of the surface of sample D showing crystals of different size.

Table 4. Data related to the crystals shown in Fig. 3.

\begin{tabular}{lccccc}
\hline Appearance & \multicolumn{2}{c}{ Iron (\%) } & \multicolumn{2}{c}{ Aluminum (\%) } & Intermetallic \\
& average & std. dev. & average & std. dev. & phase \\
Small & 7.32 & 0.11 & 0.97 & 0.30 & $\delta$ \\
Large & 6.48 & 0.45 & 0.51 & 0.26 & $\zeta$ \\
\hline
\end{tabular}

Fig. 2. Changes in the iron content of the coating as detected by the analysis of punctual X-ray spectra.

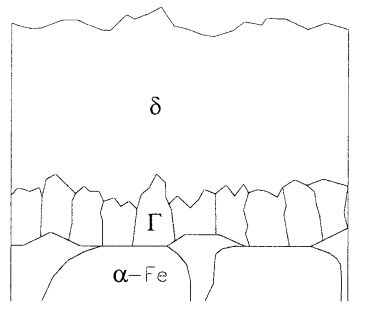

A

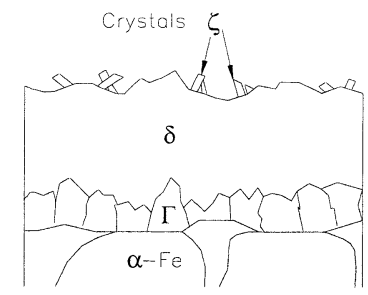

$\mathbf{B}, \mathbf{C}$

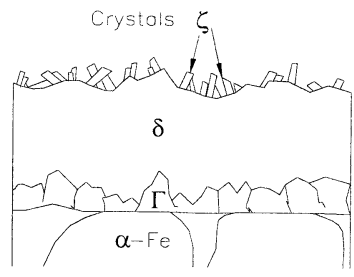

D

Fig. 4. Schematic diagram of the phases found within the different samples

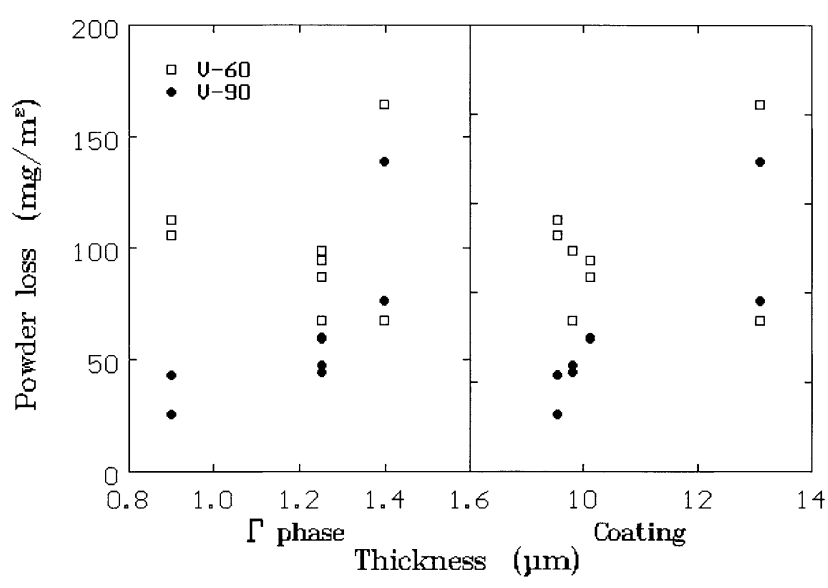

Fig. 5. Powdereing losses of samples tested in the V-die devide as a function of thickness of the phase and that of the coating.

studied by means of a reversible V-bend test. Figure 5 shows the variation of $P_{\mathrm{L}}$ as a function of either the thickness of $\Gamma$ phase or that of the total coating, and, as can be seen, the losses increased directly with the increment in thickness, independently of the geometry of the V-dies, although it is worth mentioning that the material is more sensitive to the test with $60^{\circ}$ dies, as result of the higher bending deformation.

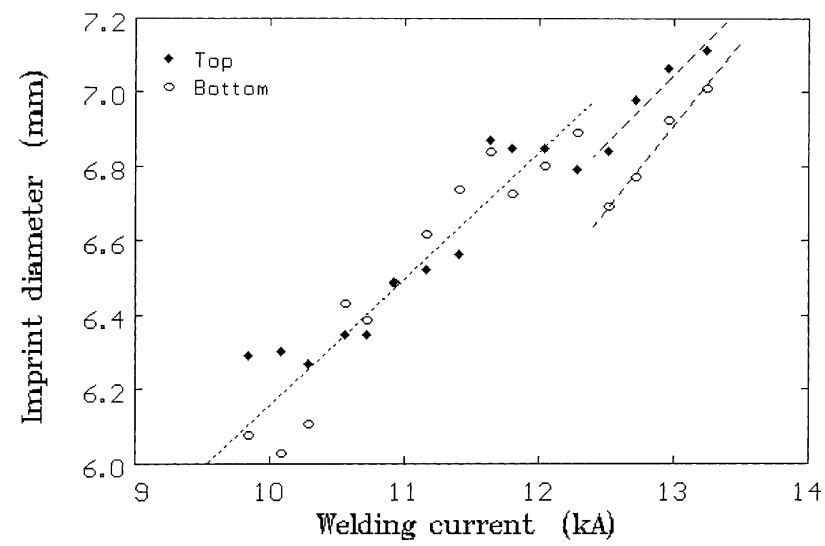

Fig. 6. Variation of the electrode imprint diameters with respect to the current used to weld different samples from batch A.

Different geometrical parameters were recorded after welding the strips. The size of the imprint diameter left by the electrodes was measured directly after welding, whereas the amount of penetration and the diameter of the welded nugget were measured after the samples were prepared for their metallographic inspection. Variation of the diameter of the imprint left by the electrodes in samples from material A can be seen in Fig. 6. It is possible to draw a single relationship for the size of the imprint, with respect to the 


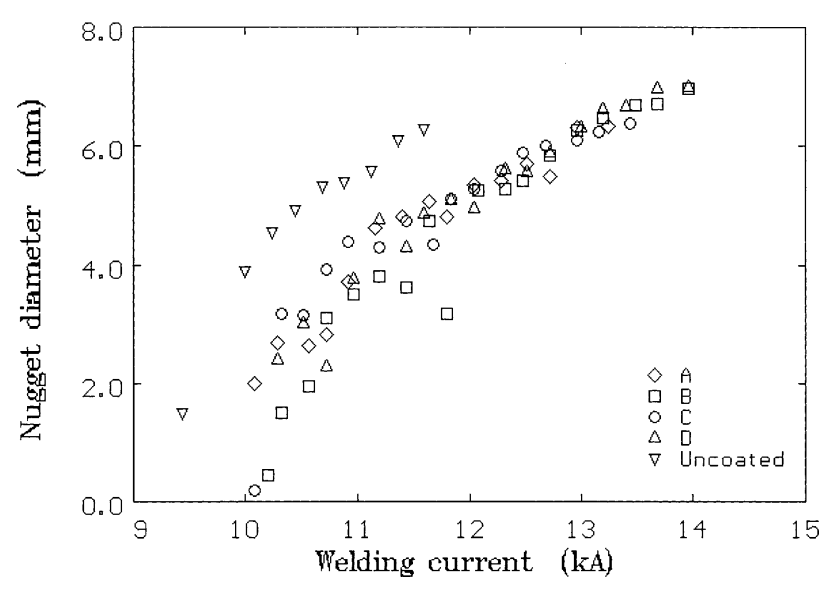

Fig. 7. Variation of the welding bead (nugget), as a function of the welding current.

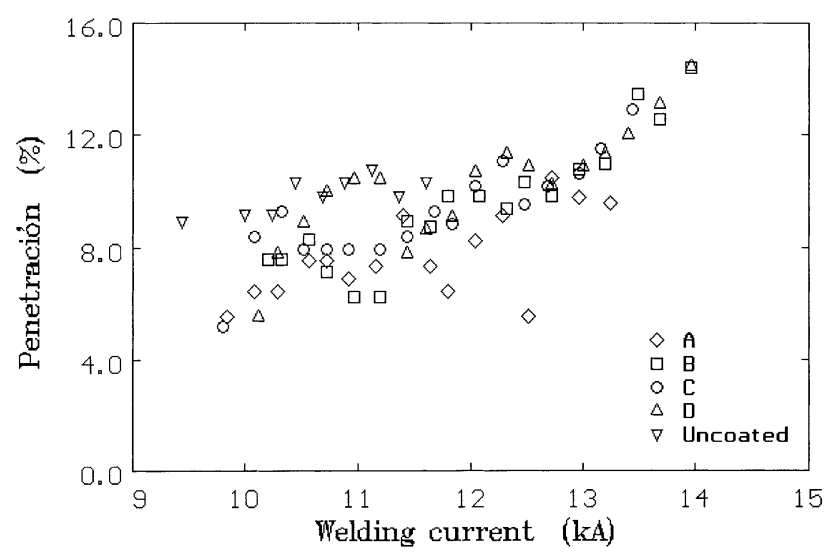

Fig. 8. Penetration of the electrodes as a function of the welding current.

welding current, left by either electrode up to a current below than $12.2 \mathrm{kA}$. Once this value is surpassed the dependence of the diameter with the current keeps being lineal, but now two different lines, one for each electrode, should be traced, and this may be due to the expulsion of the material.

Variation in the size of the welded nugget as a function of the current is shown in Fig. 7 for the different samples, data for the uncoated material is also added for comparison. All the samples exhibit a similar behavior, which is that of bigger nuggets with higher currents, but it can be observed that, for a given current applied, the size of the nuggets in the uncoated steel is around $20 \%$ bigger than those in galvannealed strips, a feature that has been attributed to the higher electrical resistance of the uncoated steel. ${ }^{14,15,17,18)}$ Penetration of the electrodes follow a similar pattern, Fig. $\mathbf{8}$, i.e. more penetration with higher current, but data for all the different samples fall within the same scatter band, although the points corresponding to the uncoated material exhibit higher penetration, as this parameter reflects the changes in the temperature dependent mechanical properties of the steel.

Expulsion of the zinc coating was observed to occur when welding the samples. Figure 9 shows a secondary electrons image of a sample from material A welded with a current of $10.72 \mathrm{kA}$, the numbers within the image indicate the positions at which punctual X-ray analysis were made,

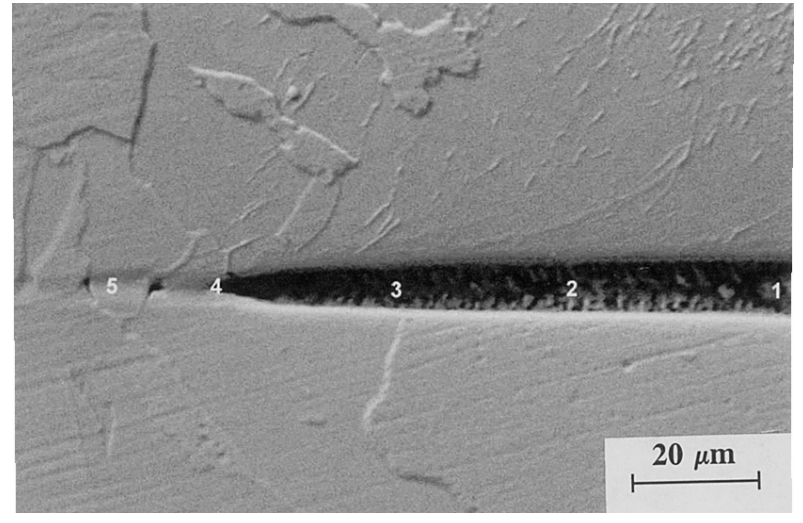

Fig. 9. Secondary electrons image of a sample that exhibited expulsion of the coating.

Table 5. Punctual analysis (wt $\%$ ) carried out on the sample shown in Fig. 9.

\begin{tabular}{cccc}
\hline Position & $\mathrm{Fe}$ & $\mathrm{Zn}$ & $\mathrm{Al}$ \\
1 & 89.65 & 9.54 & 0.80 \\
2 & 88.93 & 10.17 & 0.89 \\
3 & 92.13 & 7.52 & 0.35 \\
4 & 94.77 & 5.06 & 0.17 \\
5 & 97.73 & 2.27 & - \\
$60 \mu \mathrm{m}$ from point 4 & 99.59 & 0.41 & - \\
$120 \mu$ m from point 4 & 100.00 & - & - \\
\hline
\end{tabular}

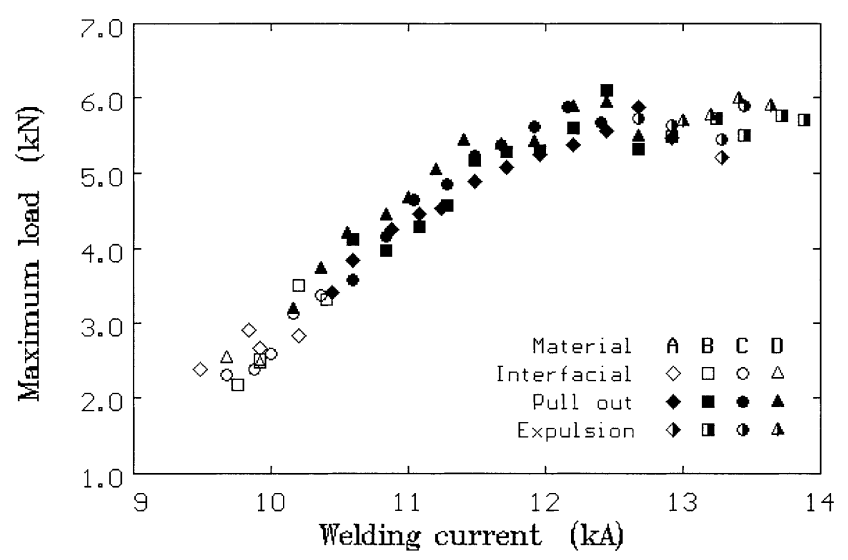

Fig. 10. Variation of the maximum tensile load as a function of the welding current.

Table 5.

Figure 10 shows the variation of the maximum load recorded during tensile testing of coated and welded samples as a function of the welding current. The data shown two different types of failure, that marked as interfacial consisted in separation of the strips due to the formation of either small or brittle nuggets, whereas in those marked as pull out, deformation and tearing of steel took place. Data points marked as expulsion correspond to those specimens in which part of the base steel was expulsed during welding, and should not be confunded with the phenomenon shown in Fig. 9. All the specimens identified as expulsion failed in the pull out mode during tensile testing. It is clear from Fig. 10 that, in the samples under study, the steel is not welded until a current of around $10.5 \mathrm{kA}$ is surpassed, whereas expulsion will not take place below $12.5 \mathrm{kA}$.

The reduction in strength of welded joints when base material is expulsed has been noticed before. ${ }^{26)}$ Although the data shown in Fig. 10 fall within a broad scatter band, 


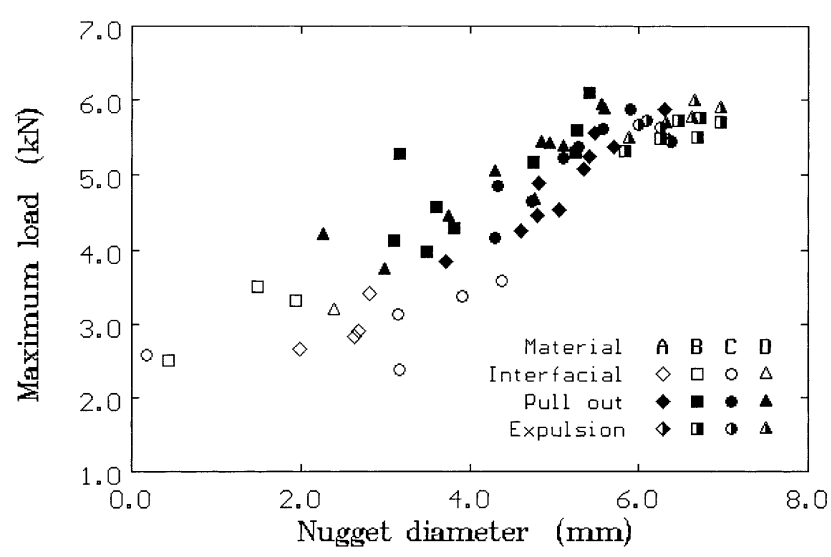

Fig. 11. Correlation between the maximum tensile load and the nugget size.

the results of strips with the lighter coatings (C and D) exhibit the tendency to resist higher loads. Previous re$\operatorname{search}^{14,15,18,19,27)}$ have established a link between the current required to weld galvannealed steels and the nugget size, or the correlation between the mechanical resistance of welded joints and the size of the nugget, ${ }^{26)}$ results that agree with the ones found in the present work. Figure 11 correlates the changes in maximum tensile load with nugget size, and, as it can be seen, the load increases with the nugget, up to the point where expulsion of base material starts to occur.

The occurrence of cracks originated at the electrode-steel interface was found in samples welded with high currents, Fig. 12. Figure 13 shows the variation of hardness measurements made on two different specimens from material $\mathrm{D}$ welded with 12.32 and $13.96 \mathrm{kA}$, the latter one corresponds to Fig. 12. Hardness was evaluated at three positions, center of nugget and at 1 and $1.9 \mathrm{~mm}$ from one of the edges; the thickness reported in Fig. 13 corresponds to that of the two joined strips. It is worth noticing that the hardness reported at mid-thickness and in the region in contact with the top electrode is the same in both samples, but that corresponding to the zone in contact with the bottom one is higher in the specimen shown in Fig. 12, and is close to the martensite expected for the low carbon content of the steel. ${ }^{28)}$ It is worth reminding that both electrodes are cooled with water, the difference between them is that as soon as the welding cycle is accomplished the top electrode is raised, and the welded piece remains on top of the bottom electrode, chilling the bottom surface of the piece.

Cracks such as the one shown in Fig. 12 did not exerted any influence on the type of failure of the specimens tested in tension as they were not in any position that will allow them to propagate, but they may be able to do if the specimens were tested in reversing bending fatigue, that was not contemplated in this work, and may cause the failure of a welded joint during actual operation.

\section{Conclusions}

It was found in the samples under study that the iron profile within the coating was affected by the settings of the galvannealing furnace, although no significative differences in the average iron content were found.

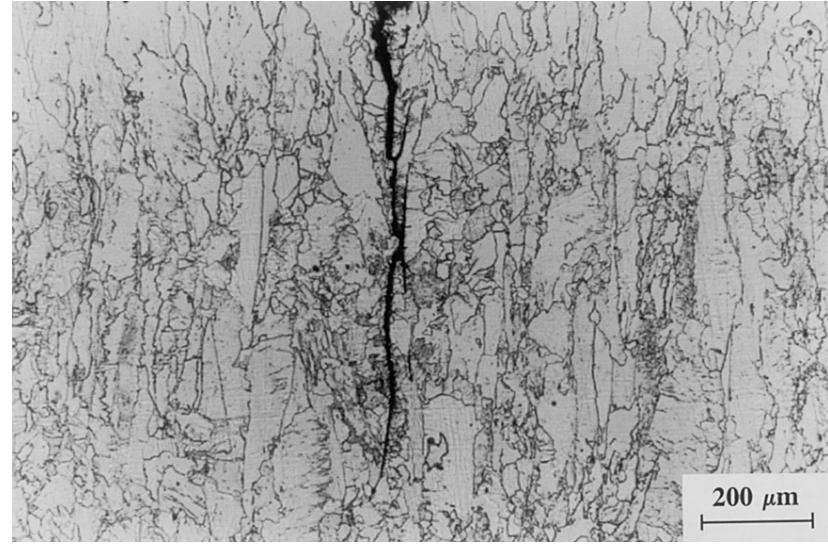

Fig. 12. Crack found in a sample from material D welded with $13.96 \mathrm{kA}$.

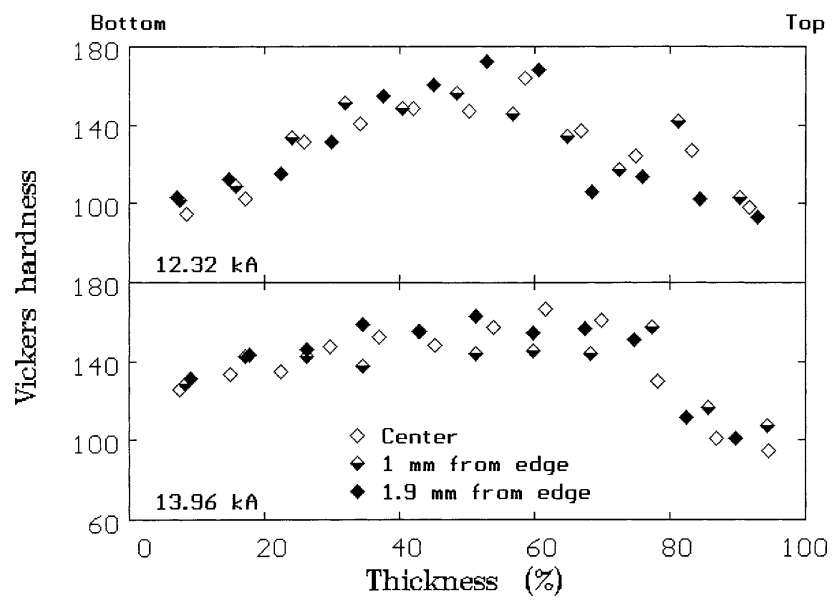

Fig. 13. Variation of hardness along the total thickness of two welded samples from material $\mathrm{D}$.

It was observed that the amount of the $\zeta$ phase decreased and that of the $\Gamma$ increased with the increment of the power setting in the furnace. The increase of the amount $\Gamma$, as well as that of the coating translated in higher amounts of powdering.

The maximum tensile load of the specimens under study increased as the current used to weld the pieces augmented up to the point where expulsion of the coating start to take place. The tendency for the samples with the thinner coating to resist higher tensile loads was observed. It was found that the size of the weldment (nugget) and the penetration of the electrodes increased with the increment in welding current, samples of steel that had their galvannealed coating removed showed the higher sizes in nugget and in penetration.

The cracks formed when welding with high currents did not seem to affect the tensile tests, but this may not be the case if the specimens are subjected to reversible bending.

\section{Acknowledgements}

The authors thank the support and facilities provided by CONACYT and SIREYES, México, as well as the material and industrial facilities provided by Galvak, S.A. de C.V. M.P.G. and R.C. recognize the support provided by PAICYT-UANL. 


\section{REFERENCES}

1) T. Kanamaru, M. Nakayama and T. Fujiwara: Recent Advances in Coated Steels used for Automobile, ed. by K. Yamakawa and $\mathrm{H}$. Fujikawa, Elsevier Science, Amsterdam, (1996), 69.

2) H. Ortiz and V. Rangarajan: 39th Mech. Working Steel Proc. Conf. Proc., Vol. XXXV, ISS, Warrendale, PA, (1997), 83.

3) C. S. Lin and M. Meshii: Metall. Mater. Trans., 25B (1994), 721.

4) T. Nakamoria and A. Shibuya: Corrosion Resistant Automotive Sheet Steels, ed. by L. Allegra, ASM International, Materials Park, $\mathrm{OH}$, (1998), 139.

5) A. T. Alpas and J. Inagaki: ISIJ Int., 40 (2000), 172.

6) A. van der Heiden, A. J. C. Burghardt, W. Van Koesveld, E. B. van Peristein and M. G. J. Spanjers: The Physical Metallurgy of Zinc Coated Steel, TMS, Warrendale, PA, (1994).

7) Y. Tobiyama, C. Kato and A. Yasuda: SAE Tech. Paper, No. 940539, (1994).

8) E. Gallo and D. K. Matlock: Galvatech '95, Conf. Proc., ISS, Warrendale, PA, (1995), 739.

9) C. Kato, H. Koumura, Y. Uesugi: The Physical Metallurgy of Zinc Coated Steel, TMS, Warrendale, PA, (1994), 291.

10) M. Urani, M. Terada, M. Yamaguchi and S. Normura: Proc. of the 1st Int. Conf. on Zinc and Zinc Alloy Coated Steel Sheet (GALVATECH '89), ISIJ, Tokyo, (1989), 478.

11) ASM Handbook, Vol. 6: Welding, Brazing and Soldering, ASM International, Materials Park, OH, (1993), 833.

12) T. B. Jefferson and G. Woods: Metals and How to Weld Them, 2nd Ed., Lincoln Electric, Cleveland, OH, (1983).

13) L. P. Connor (ed.), Welding Handbook, Vol. 1: Welding Technology, 8th Ed., AWS, Miami, (1991).

14) D. W. Dickenson: Welding in the Automotive Industry: State of the
Art, Report on AISI Project No. 1201-409C, Republic Steel Research Center, Cleveland, OH, (1981).

15) R. W. Jud: SAE Tech. Paper, No. 840285, (1984).

16) S. A. Gedeon and T. W. Eagar: Metall. Mater. Trans., 17B (1986), 879 .

17) S. A. Gedeon and T. W. Eagar: Metall. Mater. Trans., 17B (1986), 887.

18) P. Howe and S. C. Kelley: SAE Tech. Paper, No. 880280, (1988).

19) S. Mathie and P. Patou, SAE Tech. Paper, No. 850273, (1985).

20) ASTM Standard A90/A90M-95a., Standard Test Method for Weight (Mass) of Coatings on Iron and Steel Articles with Zinc or ZincAlloy Coatings, ASTM, Phyladelphia, (1995).

21) Chrysler Corporation Process Standard No. PS-9471, Detroit, (1994).

22) AWS/ANSI/SAE D8.9-97 Standard, Recommended Practices for Test Methods for Evaluating the Resistance Spot Welding Behavior of Automotive Sheet Steel Materials, AWS, Miami, (1997).

23) J. F. Song and T. V. Vorburger: ASM Handbook, Vol. 18: Friction, Lubrication and Wear Technology, ASM International, Materials Park, OH, (1992), 334.

24) ASM Handbook, Vol. 3: Alloy Phase Diagrams, 2.206, ASM International, Materials Park, OH, (1993).

25) H. Kawaguchi and Y. Hirose: The Physical Metallurgy of Zinc Coated Steel, TMS, Warrendale, PA, (1994), 153.

26) A. De, O. P. Gupta and I. Dorn: Proc. Inst. Mech. Eng., 20 (1996), 341.

27) T. V. Natale: SAE Tech. Paper, No. 860435, (1986).

28) G. Krauss: Hardenabiligy Concepts with Applications to Steel, ed. by D. V. Doane and J. S. Kirkaldy, TMS, Warrendale, PA, (1978), 221. 